\title{
MEDIA ONLINE UNTUK ASESMEN PENDIDIKAN KARAKTER TERPADU
}

\author{
Ni Made Sri Mertasari ${ }^{1}$ \\ 1 Universitas Pendidikan Ganesha, \\ Singaraja, Indonesia \\ e-mail: sri_mertasari@yahoo.com
}

\begin{abstract}
Abstrak
Pendidikan nasional berfungsi mengembangkan kemampuan dan membentuk watak serta peradaban bangsa yang bermartabat dalam rangka mencerdaskan kehidupan bangsa. Siswa tidak hanya dituntut menguasai ilmu pengetahuan dan teknologi, namun juga berkarakter sesuai jati diri bangsa. Oleh karena itu, sejak tahun 2011 dicanangkan pendidikan karakter dan dipertegas lagi pada Kurikulum 2013. Pendidikan karakter terintegrasi pada semua bidang studi, baik pembelajaran maupun asesmennya. Berbagai upaya harus dilakukan ke arah itu, seperti pengembangan model pembelajaran, model asesmen, atau media pembelajaran. Menyikapi kondisi tersebut, melalui kesempatan ini dicoba dikaji pemanfaatan media online untuk memfasilitasi asesmen pendidikan karakter terpadu. Asumsi yang dipegang adalah media online dengan berbagai wujud sudah menjadi media pertukaran dan sekaligus sumber informasi. Hasil yang diperoleh bahwa media online mampu meningkatkan kepercayaan diri siswa untuk bertanya atau berpendapat. Karakteristik media online yang asinkronus, bebas konteks, dan tidak terlalu terikat pada konvensi sosial sangat mendukung temuan tersebut.
\end{abstract}

Kata kunci: media online, asesmen pendidikan karakter

\begin{abstract}
National education serves to develop skills and form the character and civilization of dignity in the context of the intellectual life of the nation. Students are not only required to master science and technology, but also the character corresponding national identity. Therefore, since the year 2011 was declared the character education curriculum and confirmed again in 2013. Character education is integrated in all fields of study, both the learning and the assessment. Efforts must be made in that direction, such as the development of instructional models, assessment models, or learning media. Response to these conditions, the opportunity through the use of online media studied attempted to facilitate assessment of integrated character education. Held assumptions are the various forms of online media has become a medium of exchange and at the same time resources. The results that online media can improve the confidence of students to ask questions or argue. Asynchronous online media characteristics, context-free, and not too tied to social conventions strongly supports these findings.
\end{abstract}

Keywords: online media, assessment of character education 


\section{PENDAHULUAN}

Undang-undang tentang Sistem Pendidikan Nasional mengatur bahwa pendidikan nasional berfungsi mengembangkan kemampuan dan membentuk watak serta peradaban bangsa yang bermartabat dalam rangka mencerdaskan kehidupan bangsa, bertujuan untuk berkembangnya potensi peserta didik agar menjadi manusia yang beriman dan bertakwa kepada Tuhan Yang Maha Esa, berakhlak mulia, sehat, berilmu, cakap, kreatif, mandiri, dan menjadi warga negara yang demokratis serta bertanggung jawab (Depdiknas, 2003). Berbagai upaya sudah dilakukan agar fungsi pendidikan nasional dapat berjalan sesuai yang digariskan. Sejak tahun ajaran baru 2011/2012 pendidikan karakter mulai diberlakukan. Usai peringatan Hari Pendidikan Nasional Tahun 2011 Mendiknas menyebutkan bahwa bentuk pendidikan karakter diwujudkan mulai dari kurikulum sampai dengan membangun kultur budaya di sekolah (SuaraMerdeka, 2 Mei 2011). Menteri menambahkan bahwa karakter yang ingin dibangun bukan hanya kesantunan, melainkan secara bersamaan dibangun karakter yang mampu menumbuhkan kepenasaranan intelektual sebagai modal untuk membangun kreativitas dan daya inovasi.

Tahun 2013 ini Kementerian Pendidikan dan Kebudayaan menerapkan kurikulum baru yang populer dengan sebutan Kurikulum 2013. Sudah pasti hal ini merupakan salah satu upaya peningkatan kualitas pendidikan di Indonesia. Kepala Badan Pengembangan SDM Pendidikan dan Penjaminan Mutu Pendidikan menjelaskan bahwa sesuai filosofi pendidikan Indonesia yang diatur dalam UU Nomor 20 Tahun 2003 tentang Sistem Pendidikan Nasional, pengajaran pendidikan karakter melekat pada semua mata pelajaran (Kemendikbud, 28 Maret 2013). Dijelaskan pula disana bahwa Kurikulum 2013 merupakan entry point untuk memasuki sistem pembelajaran yang berkarakter. Artinya, pendidikan karakter masih mendapat perhatian yang penting.

Menteri Pendidikan dan Kebudayaan mengatakan bahwa kurikulum 2013 memiliki tujuan untuk meningkatkan rasa ingin tahu siswa dan mendorong siswa untuk aktif (Kompas, 26 Desember 2012). Berbagai standar dalam komponen pendidikan akan berubah, baik standar isi, standar proses maupun standar kompetensi lulusan. Standar penilaian pada kurikulum baru juga berbeda dengan kurikulum sebelumnya. Aktivitas siswa, termasuk aktivitas bertanya selama pembelajaran dan kemampuan menalar secara logis mendapat penekanan dalam penilaian. Uraian di atas menunjukkan bahwa kuriositas, kreativitas serta berbagai dimensi pendidikan karakter lainnya perlu mendapat perhatian yang penting, demi menciptakan anak didik yang berkarakter.

Tujuan dari pembangunan karakter adalah untuk mengembangkan karakter bangsa agar mampu mewujudkan nilai-nilai luhur Pancasila (Kemdiknas, 2011). Pendidikan karakter dimaksudkan untuk menghasilkan anak didik yang jujur, sopan, baik hati, bersikap yang baik, dan berperilaku yang baik pula. Sikap dan perilaku yang kurang baik, seperti sombong, curang, 
anarkis, dan seterusnya agar dibuang jauh-jauh karena tidak sesuai dengan nilai-nilai luhur Pancasila. Pemberian contoh atau teladan dan pembiasaan untuk bersikap dan berperilaku yang baik merupakan dasar pendidikan karakter. Sikap jujur dan bertanggungjawab disertai toleransi dan apresiasi terhadap sesama akan menumbuhkan sikap nasinalisme. Perilaku suka bekerja dibarengi dengan kreativitas yang tinggi akan menghasilkan inovasi-inovasi di berbagai bidang yang akan membawa keunggulan bangsa di tengah persaingan global.

Mendiknas menyebutkan bahwa bentuk pendidikan karakter diwujudkan mulai dari kurikulum sampai dengan membangun kultur budaya di sekolah (SuaraMerdeka, 2 Mei 2011). Menteri menambahkan bahwa karakter yang ingin dibangun bukan hanya kesantunan, melainkan secara bersamaan, dibangun karakter yang mampu menumbuhkan kepenasaranan intelektual sebagai modal untuk membangun kreativitas dan daya inovasi. Tahun 2013 ini Kementerian Pendidikan dan Kebudayaan menerapkan kurikulum baru yang populer dengan sebutan Kurikulum 2013. Kepala Badan Pengembangan SDM Pendidikan dan Penjaminan Mutu Pendidikan menjelaskan bahwa sesuai filosofi pendidikan Indonesia yang diatur dalam UU Nomor 20 Tahun 2003 tentang Sistem Pendidikan Nasional, pengajaran pendidikan karakter melekat pada semua mata pelajaran (Kemendikbud, 28 Maret 2013).

Pendidikan karakter tidak dijalankan sebagai mata pelajaran tersendiri, melainkan terintegrasi pada semua mata pelajaran yang ada. Pada prinsipnya, pengembangan budaya dan karakter bangsa tidak dimasukkan sebagai pokok bahasan tetapi terintegrasi ke dalam mata pelajaran, pengembangan diri, dan budaya sekolah (Kemdiknas, 2010). Guru harus mengintegrasikan nilai-nilai pendidikan karakter ke dalam rencana program pembelajaran (RPP) dan dalam pelaksanaan pembelajaran dikelas pada semua mata pelajaran yang ada. Siswa didorong untuk mampu melakukan evaluasi diri dan mengenali jati diri budaya bangsa, sehingga dapat bersikap dan berperilaku sesuai dengan nilai-nilai luhur Pancasila.

Pendidikan karakter bukan hanya sekedar mengajarkan mana yang benar dan mana yang salah, melainkan merupakan usaha menanamkan kebiasaan-kebiasaan yang baik sehingga peserta didik mampu bersikap dan bertindak berdasarkan nilai-nilai yang telah menjadi kepribadiannya (Kemdiknas, 2011). Pendidikan karakter mencakup pengetahuan yang baik, sikap yang baik, dan perilaku yang baik. Berbagai pengetahuan yang diterima peserta didik dari berbagai sumber hendaknya mampu disaring agar mendapatkan pengetahuan yang baik untuk diamalkan. Sikap dan perilaku yang disaksikan peserta didik baik secara langsung maupun melalui berbagai media hendaknya dapat disaring untuk memilih sikap dan perilaku yang sesuai dengan nilai luhur Pancasila.

Lickona (1997) merumuskan beberapa pendekatan untuk pendidikan karakter, antara lain pembelajaran kooperatif, menciptakan kelas demokratis, dan menciptakan 
kepedulian siswa pada kelas. Di lapangan, banyak kendala yang dialami guru untuk mengintegrasikan pelaksanaan pendidikan karakter dan mata pelajaran. Kendala dimaksud antara lain berupa keterbatasan waktu dan keterbatasan kemampuan untuk mengamati siswa yang cukup banyak, serta keterbatasan instrumen untuk merekam kemajuan belajar. Kendala tersebut perlu difasilitasi dengan segera agar kompetensi siswa yang diharapkan dapat tercapai secara optimal, baik di bidang materi maupun karakter. Pembelajaran diharapkan dapat berlangsung dengan bermakna, asesmen dapat dilakukan dengan baik, sehingga kemajuan siswa dapat direkam dengan baik, serta dapat diberi umpan balik yang relevan. Salah satu solusi yang berpeluang untuk diimplementasikan adalah penyediaan media yang dapat membantu guru menyelenggarakan pembelajaran, memberikan asesmen, dan sekaligus menyediakan umpan balik yang relevan, baik untuk matei maupun pendidikan karakter. Media yang dapat berfungsi seperti di atas adalah portal web pembelajaran yang dilengkapi fasilitas untuk menyelenggarakan asesmen secara on-line.

Infrastruktur teknologi informasi dan komunikasi yang tersedia saat ini sangat mendukung pengembangan dan pemanfaatan media tersebut. Mayoritas sekolah sudah memiliki situs web (website) dan bahkan beberapa sekolah sudah menyelenggarakan epembelajaran (e-learning). Bila situs web sekolah dilengkapi fasilitas asesmen online, maka guru dapat menyelenggarakan pembelajaran dan memberi asesmen secara online dan sekaligus menyiapkan umpan balik secara online pula. Media online membuka peluang kepada guru untuk menyelengarakan pembelajaran oleh teman sebaya (peer teaching), asesmen oleh teman sebaya (peer assessment), dan umpan balik oleh teman sebaya (peer feedback). Selain itu, media tersebut juga dapat dimanfaatkan untuk melatih mahasiswa untuk menyelenggarakan pengajuan masalah (problem posing) secara online.

Pembelajaran oleh tutor sebaya secara online sangat signifikan meningkatkan motivasi siswa untuk belajar. Media online sudah menjadi idola anak-anak untuk berkomunikasi dan mencari informasi. Pemanfaatan media online dapat meningkatkan popularitas anak secara signifikan. Apabila situasi tersebut dimanfaatkan untuk memberi peluang kepada siswa untuk membelajarkan teman sebayanya, maka motivasi mereka akan meningkat. Di lain sisi siswa yang menerima pembelajaran dapat dengan lugas bertanya kepada temannya yang menjadi tutor. Materi yang disajikan dapat sangat bervariasi, seperti teks online, teks dokumen, gambar, tabel, diagram, dan animasi. Akibatnya komunikasi yang terjadi sangat bermakna, sehingga meningkatkan kemampuan, kreativitas serta kuriositas siswa.

Asesmen dengan berbagai bentuk dapat disajikan oleh guru melalui media online. Media online membantu guru menyajikan asesmen dan umpan balik kepada siswa, baik perorangan maupun secara berkelompok. Asesmen dan umpan balik dapat berjalan timbal balik dan bekelanjutan Guru dapat menyelenggarakan portofolio online 
untuk dapat memantau kemajuan belajar siswa dengan baik, serta dapat memberi pengakuan kepada hasil karya siswa. Dengan cara seperti ini sikap mandiri, kemampuan bekerjasama, dan kesediaan mengakui karya teman sejawatnya juga dapat tumbuh.

Media asesmen online juga dapat diimplementasikan menjadi media asesmen oleh teman sebaya (peer assessment) dan sekaligus pemberian umpan balik oleh teman sebaya (peer feedback). Situasi seperti ini melatih siswa untuk bekerja keras merumuskan masalah dan dan mencari solusinya. Kesedian siswa untuk memberikan asesmen kepada teman sebayanya dapat menumbuhkan ketulusan hati pada diri siswa. Jika asesmen diberikan oleh teman sebaya, maka siswa cenderung untuk memberikan respon secara mandiri sesuai kemampuannya. Siswa juga secara bebas dapat berkreasi untuk membuat masalah, memberikan respon atau memberikan umpan balik kepada teman sebayanya. Secara tidak langsung siswa juga sudah melakukan evaluasi diri. Dengan demikian kejujuran, tanggung jawab, kreativitas, dan kuriositas siswa dapat ditumbuhkan.

Media online juga dapat dikemas sebagai media pengajuan masalah secara online (online problem posing). Awalnya, Teori pendidikan problem posing diterapkan untuk mendidik kaum tertindas sekaligus menyadarkan kaum penindas agar mereka dapat hidup berdampingan (Freire, 1996). Dalam pembelajaran di kelas, problem posing mengacu pada menciptakan masalah yang benar-benar baru atau merevisi masalah yang harus diselesaikan (Silver, 1994). Setiap tugas dapat menimbulkan satu atau lebih tugas yang lain lain. Bila problem posing dilakukan secara online, maka kerahasiaan identitas pribadi siswa selama berkomunikasi secara online dalam problem posing dapat dijamin oleh sistem. Online problem posing dapat menumbuhkan keberanian siswa untuk berkomunikasi dengan lugas, baik bertanya, menjawab pertanyaan, maupun berpendapat (Sri Mertasari, 2010). Kerahasiaan identitas dapat mendorong siswa untuk berpartisipasi dalam diskusi (Spelling dan Price, 2007).

\section{METODE}

Penelitian ini bertujuan mengembangkan perangkat lunak yang dapat bertindak sebagai media online untuk memfasilitasi pendidikan karakter terpadu. Pembelajaran yang dilaksanakan mencakup beberapa kegiatan yaitu tutorial, asesmen, dan problem posing secara terpadu untuk materi pembelajaran dan pendidikan karakter. Tutorial dan asesmen dapat dilakukan oleh guru dan oleh teman sebaya, termasuk pemberian umpan balik. Pengembangan perangkat menggunakan model prototyping yang terdiri dari beberapa langkah, yaitu pengumpulan data dan kebutuhan perangkat lunak lainnya, perancangan desain cepat, implementasi, dan evaluasi. Media online yang sudah dikembangkan dilengkapi materi berupa video pembelajaran, animasi pembelajaran, media pembelajaran berupa gambar, serta beberapa Jurnal Sains dan Teknologi |687 
dokumen pembelajaran berupa rencana pelaksanaan pembelajaran (RPP), paper atau modul.

Media pembelajaran online berupa web pembelajaran yang sudah dilengkapi materi diujicobakan di kelas riil dengan pendekatan penelitian tindakan kelas. Para guru yang menjadi sampel memberikan petunjuk kepada beberapa siswanya untuk mengakses sumber-sumber informasi pembelajaran yang ada di web pembelajaran. Siswa juga dipandu untuk melakukan diskusi, mengerjakan asesmen, memberikan umpan balik, mengajukan pertanyaan, memberi komentar, atau aktivitas pembelajaran lainnya. Akhirnya, setelah jangka waktu yang memadai kepada para siswa yang terlibat dalam proses ujicoba diberikan angket yang dilengkapi kolom untuk memberikan komentar terbatas di sekitar pemanfaatan media pembelajaran online untuk pendidikan karakter terpadu. Indikator-indikator penilaian yang digunakan antara lain kebergunaan media, keterlibatan siswa, tanggung jawab siswa, kejujuran siswa, kreativitas siswa, kuriositas siswa, dan motivasi belajar siswa. Informasi yang digali masih sangat awal, sebatas untuk mendapatkan gambaran umum efektivitas media sesuai dengan indikator-indikator yang dirumuskan.

\section{HASIL DAN PEMBAHASAN}

Media online untuk memfasilitasi pendidikan karakter terpadu sudah dikembangkan dan diujicobakan di kelas melalui penelitian tindakan kelas. Media online membuka peluang terjadi pembelajaran dengan tutor sebaya secara online, asesmen oleh teman sebaya secara online, pemberian umpan balik oleh teman sebaya secara online, dan problem posing secara online, yang mana semua itu memberi kesempatan kepada siswa untuk berinteraksi secara optimal. Bila dalam pembelajaran terjadi interkasi yang bekelanjutan, maka pendidikan karakter akan berkembang dengan baik. Berkowitz dan Bier (2005) menemukan bahwa modifikasi pembelajaran dengan membuka peluang kepada siswa untuk berkolaborasi dan bertanggungjawab sangat bermanfaat dalam pendidikan karakter. Norhayati dan Siew (2004) menemukan hal serupa bahwa teknologi informasi dan komunikasi dapat bekerja mandiri memberikan layanan pendidikan interaktif kepada siswa, termasuk pendidikan moral.

Kemampuan teknologi informasi dan komunikasi mengintegrasikan teks, gambar, diagram, grafik, animasi, dan suara dapat dimanfaatkan untuk menciptakan realitas maya, sehingga pembelajaran dapat dibuat mendekati kontekstual.

Permasalahan pembelajaran dapat dibuat kontekstual maya, sehingga siswa dapat bersikap dan berperilaku sesuai dengan yang tuntutan. Guru dapat memberi penguatan terhadap sikap dan perilaku yang benar, dan sebaliknya dapat mengarahkan sikap dan perilaku yang masih menyimpang. Umpan balik dari guru kepada siswa juga disajikan dengan bantuan TIK, sehingga memudahkan guru. Lee dan Lim (2012) menemukan beberapa kelebihan asesmen teman sebaya dalam blended 
learning, antara lain ada pada pesan manajerial, prosedural, dan sosial. Kondisi seperti ini akan membangkitkan motivasi belajar siswa, menumbuhkan kuriositas siswa, menurunkan kecemasan siswa, menumbuhkan kreativitas siswa, serta meningkatkan rasa percaya diri siswa.

Komunikasi online juga

mendorong penumbuhan jiwa demokratis. Kebebasan mengajukan pertanyaan dan memberi tanggapan mendorong siswa menghargai pendapat orang lain. Siswa juga terlatih untuk memberikan penghargaan terhadap kinerja teman, sehingga motivasi belajar temannya semakin berkembang. Sekecil apapun pendapat siswa akan tertampung di basis-data dan berupaya diberikan umpan balik. Akibatnya, rasa percaya diri siswa akan tumbuh dan lebih terdorong untuk mengajukan pendapat, pertanyaan atau tanggapan berikutnya. Semua pertanyaan dan pendapat siswa akan terekam menjadi portofolio yang dapat dibuka kembali setiap saat. Dengan cara seperti ini siswa dapat berinteraksi secara optimal.

Komunitas belajar online memberi peluang kepada siswa untuk dapat mengakses materi dari berbagai situs secara simultan, baik berupa teks, audio, atau video (Candiasa, 2011). Aaron \& Chigubu (2006) mendukung temuan tersebut dengan menyarankan agar siswa dibelajarkan dalam situasi yang aktif dan menyenangkan untuk mendapatkan ketrampilan untuk unggul dengan cara menyiapkan mereka sumber-sumber belajar yang tepat.Siswa dapat berinteraksi dengan guru dan siswa dari berbagai cara. Siswa dapat secara mandiri mengatur pembelajarannya dan guru dapat meningkatkan kemampuannya untuk mengelola pembelajaran melalui kolaborasi dengan koleganya. Beberapa siswa berpengalaman mengungkapkan kesulitan belajarnya dan bahkan mengajukan pertanyaan kepada kolega dari sekolah lain yang belum pernah mereka kenal. Siswa memiliki kesempatan untuk mengakses materi dari lingkungan yang lain, bukan hanya dari lingkungan lokal mereka untuk memperluas wawasan. Dengan demikian siswa dapat belajar dengan nyaman serta berkomunikasi dengan lugas dengan siswa lainnya dan dengan guru secara online. Anderson (2006) menemukan bahwa melalui pembelajaran online, siswa dapat belajar dengan nyaman dengan berkomunikasi satu sama lain secara on-line.

\section{SIMPULAN}

Media pembelajaran online untuk memfasilitasi pendidikan karakter terpadu yang dikembangkan secara umum dapat memfasilitasi pembelajaran yang direncanakan. Siswa dapat dengan lugas bertukar informasi pembelajaran serta berkomunikasi dengan guru dan teman sebayanya dalam berbagai kondisi. Beberapa karakteristik media online seperti bebas konteks, relatif bebas konvensi sosial, serta dapat menjamin kerahasiaan individu dapat menjadi kelebihan dari media online. Tutorial online, asesmen online, dan pemberian umpan balik online baik oleh guru maupun dapat berjalan dengan baik. Kondisi bebas konteks dan relatif bebas konvensi sosial membuat siswa dapat memberi penjelasan, bertanya, atau menyampaikan respon secara iklas 
sesuai kemampuan yang dimiliki. Kondisi seperti ini sangat bermanfaat untuk melatih keiklasan dan kejujuran siswa. Selain itu, siswa juga dapat memberikan respon secara lugas tanpa ada perasaan cemas atau tertekan. Apalagi dengan kerahasiaan individu terjamin, siswa akan lebih berani bertanya, memberi respon atau berpendapat tanpa ada perasaan cemas kalau kelemahannya diketahui teman. Kondisi ini sangat menguntungkan dalam hal melatih keberanian siswa melakukan penyajian materi, bertanya, merespon, berpendapat, dan sekaligus menghargai pendapat atau karya orang lain. Dengan demikian, sikap demokratis siswa dapat tumbuh dengan baik. Kelemahan yang ada pada media online memang ada, seperti dapat menimbulkan keterasingan anak akibat terlalu banyak berinteraksi dengan komputer atau dapat memberi pengaruh negatif akibat informasi yang bersifat memprovokasi, porno atau radikal. Pengaruh negatif tersebut diupayakan dihindari dan dikendalikan. Pemanfaatan media online harus diupayakan dalam pembelajaran disertai rasa optimis bahwa media online lebih banyak memberi pengaruh positif, baik untuk kompetensi akademik maupun pendidikan karakter.

\section{DAFTAR PUSTAKA}

Aaoron, Ashley \& Mercy Tsiwo-Chigubu. "Present Day Students a.k.a Victims of Standardized Testing." National Forum of Teacher Educational JournalElectronic, Volume 16, Number 3, 2006.

Andersson, Aneka, "Seven Major Challenges for e-learning in
Developing Countries." Education Journal of Education and Development Using ICT, Volume 2, Number 4, 2006.

Berkowitz, Marvin W. and Melinda C. Bier. "What Works In Character Education: A research-driven guide for educators." Character Education Partnership, February 2005.

Candiasa, I Made. "Modul Hiperteks dengan Evaluasi Online Sebagai Suplemen Pembelajaran Reguler Di SMA dalam Upaya Peningkatan dan Pemerataan Mutu Pendidikan," Jurnal Penelitian dan Pengembangan Pendidikan , Vol. 5, No.1, April 2011.

Depdiknas, 2003, Undang-undang Nomor 20 Tahun 2003 tentang Sistem Pendidikan Nasional, Jakarta:

Departemen Pendidikan Nasional.

Freire, Paolo, 1996, Pedagogy of the Oppressed, Penguin (First published in 1970).

Kemdiknas, 2010, Panduan Pelaksanaan Pendidikan Karakter, Jakarta: Kementerian Pendidikan Nasional.

Kemdiknas, 2011, Pengembangan Pendidikan Budaya dan Karakter Bangsa, Jakarta: Kementerian Pendidikan Nasional.

Kemendikbud, 28 Maret 2013, Pendidikan Karakter Melekat pada Semua Mata Pelajaran, http://kemdikbud.go.id/kemdikb ud/berita/1165

Kompas, 26 Desember 2012, Ini Standar Penilaian dalam Kurikulum 2013.

Jurnal Sains dan Teknologi|690 
Lee, H.-J., \& Lim, C. (2012). "Peer Evaluation in Blended Team Project-Based Learning: What Do Students Find Important?" Educational Technology \& Society, 15 (4).

Lickona, Thomas. "The Teacher's Role in Character Education." Journal of Education, Volume 179, Number 2, 1997.

Norhayati, A. M., \& Siew, P. H. (2004). "Malaysian Designing Perspective: Multimedia Interactive Learning Environment for Moral Values Education." Educational Technology \& Society, 7 (4).
Silver, E. A., 1994,. On mathematical problem solving. For the Learning of Mathematics.

Spellings, Margaret and Deborah A. Price. 2007. "Evidence-Based Mobilizing Character Education. U.S. Department of Education." http://www.ed.gov/about/offices /list/ osdfs/index.html.

Sri Mertasari, Ni Made. "Evaluasi Berbasis Komputer." Jurnal Penelitian dan Pendidikan UNDIKSHA, Vol. 1, No. 3, April 2010

SuaraMerdeka, 2 Mei 2011, Mendiknas: Pendidikan Karakter Segera Diterapkan 